This item was submitted to Loughborough's Research Repository by the author.

Items in Figshare are protected by copyright, with all rights reserved, unless otherwise indicated.

\title{
Joint position stand of the ISSP, FEPSAC, ASPASP, and AASP on professional accreditation
}

PLEASE CITE THE PUBLISHED VERSION

https://doi.org/10.1016/j.psychsport.2018.06.005

PUBLISHER

(C) Elsevier

VERSION

AM (Accepted Manuscript)

\section{PUBLISHER STATEMENT}

This paper was accepted for publication in the journal Psychology of Sport and Exercise and the definitive published version is available at https://doi.org/10.1016/j.psychsport.2018.06.005

LICENCE

CC BY-NC-ND 4.0

\section{REPOSITORY RECORD}

Schinke, Robert J., Gangyan Si, Liwei Zhang, Anne-Marie Elbe, Jack Watson, Chris Harwood, and Peter C. Terry. 2019. "Joint Position Stand of the ISSP, FEPSAC, ASPASP, and AASP on Professional Accreditation". figshare. https://hdl.handle.net/2134/34074. 
1 Running Head: International Accreditation Position Stand

2

3

4

\section{Joint Position Stand of the ISSP, FEPSAC, ASPASP, and AASP on Professional}

\section{Accreditation}

Robert J. Schinke ${ }^{1}$, Gangyan $\mathrm{Si}^{2}$, Liwei Zhang ${ }^{3}$, Anne-Marie Elbe ${ }^{4}$, Jack Watson ${ }^{5}$, Chris Harwood $^{6}$, \& Peter C. Terry ${ }^{7}$

School of Human Kinetics, Laurentian University, Canada ${ }^{1}$

Hong Kong Sport Institute, Hong Kong ${ }^{2}$

Psychology School, Beijing Sport University, China ${ }^{3}$

Institute of Sport Psychology and Sport Pedagogy, Leipzig University, Germany ${ }^{4}$

College of Physical Activity and Sport Sciences, West Virginia University, United States ${ }^{5}$

School of Sport, Exercise, and Health Sciences, Loughborough University, United Kingdom ${ }^{6}$

Division of Research \& Innovation, University of Southern Queensland, Australia ${ }^{7}$

Corresponding Author: Robert J. Schinke

School of Human Kinetics

B-241 Ben Avery Building

Laurentian University

935 Ramsey Lake Rd.

Sudbury, Ontario

P3E-2C6

E-mail: rschinke@laurentian.ca

Keywords: Cultural Sport Psychology, Europe, Historical Perspectives 
27 Highlights for Review

28

1. The historical backdrop of ASPASP, FEPSAC, AASP, and ISSP has contributed to their quest for improved accreditation standards.

2. Accreditation continues to unfold in international societies and is influenced by the societal mission.

3. Suggestions are made for how these societies might work together to augment global standards in applied sport/exercise psychology and mental training. 
36 Abstract

37 Objectives

38 To situate the current status of accreditation in four key international societies, ASPASP,

39 FEPSAC, AASP, and ISSP, in a historical backdrop and then to draw on these approaches to

40 propose future directions and developments relating to practical standards.

41 Design

42 A review of the origins and current status of accreditation in four international sport psychology societies is utilized to situate the recent prominence of professional standards and the importance of these in our global professional community. This review is written temporally from past, to present, to future prospects.

Method

A presentation of societal accreditation foci is situated temporally using the following structure: (a) emergence and historical backdrop from each society, (b) emergence and reasoning for accreditation, (c) current societal standards/status of accreditation, (d) future developments in the society's accreditation system, and (e) reflections and recommendations for global standards, with suggestions of how this might be accomplished.

\section{Results}

The presentation of scholarship is intended to serve as a form of advocacy for improved accreditation standards within the global professional community. The societal perspectives call for a balance between localized cultural infusion and proposed global guidelines upon which professionals might meet a converged reasonable practice threshold.

\section{Conclusions}

Sport psychology accreditation is increasingly important as the applied realm of this profession spans community physical activity/recreation, and developmental and elite/professional sport. Accredited practices must integrate universal and local approaches. 
Explorations into sport psychology (also comprised of exercise) credentialing are not recent. There exist rich histories in multinational societies and geographic regions, spanning over 30 years (e.g., http://www.appliedsportpsych.org/about/our-history/). Recognizing the importance of accreditation has been necessary in fostering understanding about the competencies needed to practice effectively in this field (see Silva, 1984). Epstein and Hundert (2002) have defined competency in medical education and adopted in psychology and allied professions (see Fouad et al., 2009) as “habitual and judicious use of communication, knowledge, technical skills, clinical reasoning, emotions, values, and reflections in daily practice” (p. 226). These competences are in terms of processes and outcomes meeting these standards, and vary by region and country (Tenenbaum, Lidor, Papaioanno, \& Samulski, 2003). Lately, there has been increased focus on international and national credentialing of individual practitioners (e.g., Hutter, van der Zande, Rosier, \& Wylleman, 2016). The Association for Applied Sport Psychology (AASP) has aligned with national certification standards, and shifted to a written examination as part of its assessment (http://www.appliedsportpsych.org/certification/become-certified/). The European Federation of Sport Psychology (FEPSAC) is underway in developing its own continental accreditation (http://www.fepsac.com/certification/), whilst the Asian-South Pacific Association of Sport Psychology (ASPASP) has implemented a free online professional course (http://www.aspasp.org/professional-development) as a first step towards accrediting practitioners in the region. Entering into this movement, the International Society of Sport Psychology (https://www.issponline.org/issp-r) is now well underway in launching an international registry of qualified professionals, based on global baseline standards. By no means do the international societies reflect all of the global credentialing developments. There are continental societies in Africa and South America engaged in dialog with our authors, seeking minimum acceptable standards in the regions where they practice. The focus in this 
paper is delimited to ASPASP, FEPSAC, AASP, and the ISSP, as these four societies have formally undertaken forms of credentialing in the broad field of sport psychology, encompassing both psychologists and sport scientists. Moreover, these four societies operate at the very least at the continental level, as opposed to credentialing in a single country, focusing particularly on sport psychology rather than the broader field of psychology. Sport psychology is now well represented across the world, and with this expansion, formally accredited practitioners have become an international focus.

This manuscript has been developed to spur further dialog regarding accreditation standards in the domain largely defined as sport and exercise psychology, including its two approaches of psychology and sport science orientations to the field. Within this manuscript, the aforementioned four societies have partnered, with three societal presidents (ASPASP, FEPSAC, ISSP), one society’s past president (AASP) appointed by its society and two colleagues centrally involved in the design of their society’s educational courses engaged, utilizing the following structure. Each society has discussed (a) the origins and historical backdrop of its society, (b) the emergence and evolution of discussions relating to accreditation, and (c) the current status of the society's actions in terms of developing or revisiting its professional standards. Thereafter, the authors have engaged collaboratively in the development of a synthesis, in the form of postulates. The intention is to identify the convergences and divergences within and across these societies, to explore pathways to augment international professional standards through credentialing.

\section{Working Terminology}

To better understand the diverse perspectives that have informed this international discussion necessitates clarification of three key concepts: accreditation, certification, and registry. These three terms have been employed in the formation of credentialing, as societies have reflected upon how best to achieve suitable standards in their regions, whilst supporting 
111 professional members and protecting these members’ prospective clients. The most general

112 among these is accreditation; an umbrella term spanning types of professional designations.

113 The term accreditation refers to a professional benchmark to be achieved and maintained by a

114 regulatory group, such as a society, one that is usually a non-government organization

115 (Rooney \& van Ostenberg, 1999). All forms of accreditation are voluntary and designed to

116 meet a reasonable standard of theoretical and practical competence (e.g., psychology, sport

117 psychology, exercise science, measurement, assessment and interpretation, ethics, see

118 Tenenbaum et al., 2003), and thereafter to further oneself in conformance with the dynamic

119 nature of an affiliated accreditation system, so as to remain current. This step is taken to

120 strengthen the public's confidence in the standards and the potency of the specific credential.

121 According to Zaichkowsky and Perna (1996), accreditation might apply to educational

122 standards within learning institutions or as discussed herein, to standards for individuals.

123 There are distinctions in sport psychology accreditation that have, or are presently

124 being chosen by associations and societies, based upon their members' nationalities. These

125 distinctions ought not to be judged as of higher or lower level standard, such as whether one

126 type might be more exacting than a second (Tenenbaum et al., 2003). There are reasons why

127 an accreditation is chosen as best suited to a society, in a given region or country.

128 Considerations might include varied qualities of formal education, access to knowledge, and

129 also the availability of professional training and mentoring, among further reasons in each

130 locale (see Hutter et al., 2016). The types of accreditation our societies focus on are non-

131 statutory, unprotected by law (i.e., certification or registry) as compared to licensure.

132 Certification has often been used interchangeably with accreditation, as both terms

133 originate from an authorized body, be it governmental or a non-governmental agency, where

134 one meets pre-established standards or criteria. However, in the case of certification, the focus

135 is narrowed to individuals as opposed to organizations. Universities might become accredited 
136 by a society or association as meeting curriculum standards, whereas individuals can become certified members (see Rooney \& van Ostenberg, 1999). Discussions within AASP have been undertaken to credential programs meeting specific standards and course content. However, herein we have focused on the accreditation of individuals, given that this is where developmentally the global community is presently placing its emphasis. The term registry is somewhat different, referring to "the identification of individuals who have completed both training and experience requirements for membership in their professional group” (Adams, 2006, p. 62). With these nuances, we turn to approaches within the named societies. Table 1 includes credentialing details developed in relation to ASPASP, FEPSAC, AASP, and ISSP.

\section{Asian-South Pacific Association of Sport Psychology (ASPASP)}

In 1988, at the Olympic Scientific Congress in Korea, Robert Singer, then President of the ISSP, encouraged Atsushi Fujita from Japan to lead the development of an international body of sport psychology in the Asian-South Pacific region. Fujita called a meeting at the 1988 Olympic Congress to discuss the possibility of establishing the Asian-South Pacific Association of Sport Psychology (ASPASP). Atsushi Fujita, M. L. Kamlesh (India), and Miki Bar-Eli (Israel) were among the delegates who attended that meeting. Then in 1989 during the $7^{\text {th }}$ ISSP World Congress in Singapore, ASPASP was formally established (T. Morris, personal communication, March 23, 2017). Fujita was elected as the society’s first president. Since its inception, ASPASP has grown steadily while remaining affiliated with the world body, the ISSP. The ASPASP Managing Council is comprised of 14 members:

President, Past-President, three Vice-Presidents Secretary General, Treasurer, and seven National Representatives. ASPASP currently has a membership with representation from 24 countries. ASPASP has held its official international congress every three to four years since 1991, with the most recent being held in Daegu, Korea in 2018. 
The development of a robust yet workable accreditation process has progressively become a central focus within ASPASP, stemming from the variability in national accreditations. To date, accreditation systems across the Asian-South Pacific region have ranged from highly structured and rigorous systems in some countries to completely nonexistent processes in others. In Australia, the accreditation system was developed by the Psychology Board of Australia and approved by the Australian Health Workforce Ministerial Council. Sport and exercise psychologists must first gain general registration as a psychologist and then complete the requirements for their specialist area of practice endorsement. To be eligible for endorsement, a registered psychologist must have: (1) an accredited doctorate in one of the approved practice areas and a minimum one year of approved, supervised, full-time equivalent practice with a board approved supervisor; or (2) an accredited master's degree in one of the approved practice areas, and at least two years of approved, supervised, full-time practice with a board approved supervisor; or (3) another qualification that in the board's opinion, is equivalent to (1) or (2).

The Korean Society of Sport Psychology (KSSP) developed a three-level accreditation system for sport psychology consultants in 2004 and will deliver its 24th Sports Psychological Counselor Qualification Training in 2018. Currently, there are more than 800 certified sport psychology consultants in Korea. A Level 1 sport psychology consultant reflects accreditation at the highest level, and is required to have (1) gained a doctoral degree in sport psychology or a related field, or Level 2 certification; (2) completed a specific educational curriculum; (3) passed the Level 1 exam; (4) completed a practicum under a certified supervisor of 200 hours, delivered two oral case presentations in academic conferences; and (5) completed 50 hours of workshops, seminars, and/or training courses recognized by KSSP. A Level 3 sport psychology consultant needs to have (1) gained certification associated with physical education or health/sport disciplines, or work experience in the sport and exercise-related field 
185 for two years; or (2) be a current college student majoring in physical education and/or a

186 sport-related discipline; and (3) completed a specific educational curriculum, and (4) passed 187 the Level 3 exam.

188 The China Sport Psychology Association (CSPA), a third example, started its

189 accreditation program in 2007 when 20 sport psychologists were accredited as Level 1 sport

190 psychologists. The CSPA accreditation system also has three levels. The accreditation

191 standard for Level 1 (the highest) requires applicants to have (1) a Ph.D. degree closely

192 related to sport psychology or be in an academic position at associate professor or above; (2)

193 at least 400 hours of supervised practice; (3) at least five years of consulting experience; (4)

194 two peer-reviewed papers as first author at international level in the past three years; and (5)

195 passed an oral examination. Level 2 requires applicants to have (1) a master’s degree related

196 to sport psychology or be in an academic position in this field as a lecturer; (2) more than 200

197 hours supervised practice; (3) at least two years of consulting experience; (4) two peer-

198 reviewed papers as first author at national level in the past three years ; and (5) passed an oral

199 examination. Level 3 requires (1) a bachelor degree in psychology or physical education; (2)

200 one peer reviewed paper as first author at national level; and (3) pass an oral examination.

201 ASPASP online course. Following from the national accreditations exemplified above, 202 discussions have been ongoing to develop more standardized criteria across Asian and South 203 Pacific countries to address discrepancies between accreditation systems across the region 204 and, in particular, to develop some form of accreditation where none current exists. ASPASP 205 has two possibilities to improve accreditation. The first option is to encourage national sport 206 psychology associations to align their accreditation system with that of their national 207 psychology association. The practice of Australian sport psychologists aligns with this model. 208 The second possibility is to set up an international accreditation system within ASPASP or 209 ISSP. ASPASP has developed an open online course in sport psychology as the first step 
towards a more standardized accreditation. Following its release in 2015, the online course

211 Elite Sport Performance: Psychological Perspectives (Terry \& Martin, 2015) has received over 128,000 page views from 125 countries. Within the ASPASP region, the greatest engagement has come from Australia, Singapore, Malaysia, Taiwan, and the Philippines. In a 145-day period in 2015-2016, following the release of the course, $20 \%$ of the 1,007 enrolees received a certificate of completion having finished nine learning modules and submitting a mental training program designed for one of eight hypothetical elite athletes, each presenting with different performance issues. A total of $27 \%$ of learners completed all modules, and 51\% completed some modules. These engagement statistics exceed the mean for massive open online courses (MOOCs), which typically have about a 12\% completion rate (Jordan, 2015). Despite minimal promotion of the course since 2016, a further 400 participants have enrolled. The course design (see Martin, Kelly, \& Terry, 2018) promotes self-paced and autonomous learning and takes a recommended 40-80 hours to complete. There are opportunities for genuine choice and deeper exploration of learning concepts of particular interest. Learning tasks, deadlines, and assessment requirements are kept to a minimum, in recognition of the MOOC context in which attrition is never more than one click away. The course and accompanying e-book, Secrets of Asian Sport Psychology (Terry, Zhang, Kim, Morris, \& Hanrahan 2014) , are both linked from the ASPASP website (www.aspasp.org) and represent tangible examples of the organisation’s commitment to raising the standard of sport psychology services in the Asia-South Pacific region. Furthermore, both Secrets of Asian Sport Psychology (Terry et al., 2014) and Elite Sport Performance: Psychological Perspectives (Terry \& Martin, 2015) are free open educational resources, allowing others to use and repurpose them in line with the Creative Commons licence (CC-BY; see http://creativecommons.org.au/) applied to both resources. 
Eastern and western influences on accreditation. Cultural differences are a long-

standing topic of interest in psychology, which Hofstede (1980) unpacked into four dimensions: individualism-collectivism, power distance, masculinity-femininity, and uncertainty avoidance. Given the global nature and dynamics of cultural diversity within the sporting arena, exemplified by the various sport systems and cultural characteristics in training and competition, it is important to consider the contribution of diverse cultures to the knowledge and understanding of sport psychology. An ongoing thrust within ASPASP has been to promote culturally-specific systems of mental training implemented in the form of psychological services offered to athletes participating in the Olympic Games.

In China, for example, the base for athlete mental skills development is a techniqueoriented level of psychological training, including goal-setting, relaxation, imagery, biofeedback, and various other mental skills, originally from western sport psychology. At the top of the system is a vision-oriented level, including calligraphy, education of Buddhism for self-control, and using a dialectic approach as a way to understand the true meaning of winning and losing. Multiple accounts of psychological training and consultation experiences (Ding et al., 2014; Si, Yue-Li, \& Chen, 2016; Zhang, 2017) have confirmed that Chinese athletes benefit from both western and eastern methods in their Olympic psychological preparation. The integration of diverse psychological approaches and techniques has allowed practitioners throughout the ASPASP region to assist athletes with culturally diverse competencies.

\section{Federation of European Sport Psychologists (FEPSAC)}

The European origins of sport psychology date back to people such as Wilhelm Wundt (Leipzig), who published on the relationship between physical strain and mental performance at the end of the $19^{\text {th }}$ century (Terry, 2011). Researchers in France, Italy and Hungary were interested in similar topics during that time (e.g., Bäumler, 2002; Kunath, 2003). These 
positive developments in the field were dampened by World War I. After the end of WWI the first sport psychology labs were established by Robert Werner Schulte in Berlin and P. A. Rudik in Moscow. Avksenty Puni's work conducted at the lab in Leningrad in the 1930s also became famous (Ryba, Stambulova \& Wrisberg, 2005). However, once again, these positive developments came to a halt due to World War II which nearly destroyed the continent, including its research infrastructure. The development of sport psychological research was further impacted after WWII when Europe was separated into two political blocks and, consequently, Olympic sport was used to demonstrate superiority of political systems.

The European Federation of Sport Psychology was founded in 1969. One of FEPSAC's goals was also to encourage networking of sport psychologists from the two different political systems. The establishment of FEPSAC also allowed for an exchange between the two political systems with FEPSAC presidents originating from Eastern and Western systems in the first 16 years of its existence. Nevertheless, Europe's political divide and language diversity made it difficult for European sport psychologists to read each other's work, travel freely to attend conferences and discuss ideas about their profession. Even if the language diversity and the economic imbalance within Europe remain challenging for the promotion of sport psychology today, the unification of Europe has contributed with many positive aspects that have enhanced the development of our field. The establishment of the European Master’s Program in Sport and Exercise Psychology in 1996-1997 (Vanden Auweele, 2003) and later, the prestigious Erasmus Mundus Program in Sport and Exercise Psychology as well as the open labor market in Europe and the unification of the study system (Bologna), have all contributed to mobility within Europe. The unification of Europe and the fall of the Iron Curtain have also led to the spread of English. Also, the establishment of ENYSSP (European Network of Young Specialists in Sport Psychology) has contributed to the international exchange of young scholars in research, practice and education. ENYSPP 
has been much more successful than FEPSAC in recruiting MC members from Eastern Europe and hosting their annual conferences in countries with a Soviet past.

$$
\text { There remains a lot to be achieved to better balance access to resources, skills and }
$$

knowledge exchange. This imbalance is in part caused by economic inequality, which impacts access to journals, books and conferences, but it is also caused by the diversity in languages spoken in Europe. Furthermore, there is an imbalance in educational opportunities for practitioners. While some parts of Western Europe have sophisticated and longstanding educational programs, there are still regions of Europe without educational opportunities in sport psychology at their universities, and without postgraduate educational programs for practitioners. Although there has been an increased focus on ensuring the quality of sport psychological services, for example, in German speaking countries (Kellmann, Gröpel \& Beckmann, 2011), and formalized supervision has become an integral part of the education of applied practitioners in many European regions (e.g., Stambulova, Johnson \& Linner, 2014), there are no European-wide guidelines for practitioners' formation and continuing education. EFPA, the European Federation of Psychologists, established a Task Force in Sport Psychology in 2011 with the goal to create a specialization in sport psychology for practitioners who have a EuroPSY qualification - a European standard of education and professional training in psychology that includes a 5-year university education and one year of supervised practice. The FEPSAC Managing Council (MC) elected in 2015 also formulated the goal to outline minimum European-wide criteria for specialists in applied sport psychology. These criteria were aimed at giving guidance to colleagues from countries without adequate educational opportunities and a national certification system. EFPA’s Task Force, however, did not manage to submit a proposal to the General Assembly at the European Congress of Psychology in Amsterdam in 2017 and the Task Force was subsequently terminated. Since it is currently unclear how this work under the guidance 
of EFPA will continue, it has become even more important for FEPSAC to establish its own guidelines. Since this EFPA certification/specialization would not allow practitioners with a background in sport science to become certified practitioners in applied sport psychology, FEPSAC embarked on establishing its own European-wide criteria for specialists in applied sport psychology. This endeavor was supported by EASY (Educators in Applied Sport Psychology; Hutter, 2014) who supplied information on the European educational systems in sport psychology and provided extensive feedback on FEPSAC's first drafts of these criteria.

FEPSAC certification. Professional certification is a crucial element in the establishment, legitimization, and reputation of a profession. The FEPSAC MC developed certification guidelines for specialists in applied sport psychology, establishing a certification process to distinguish these professionals from others in the marketplace (e.g., performance enhancement consultants, mental skills trainers, mental coaches). The goal of this initiative is to define the minimum standards that should be met by individuals in order to qualify for independent practice. The certification process focuses on the standards for practitioners who have an initial qualification background in sport science, psychology, or both. FEPSAC believes that practitioners should have high standards of training and delivery using and complementing the expertise specific to their initial training. It is also important for FEPSAC that the path to certification is not only open for psychologists but also for sport scientists, as is common practice in several European countries, such as Germany, France and Finland. FEPSAC carefully examined several certification systems across Europe, meeting with individuals and international organizations involved in certification, continuous professional development, education and training, as well as legal aspects of certification, in order to guarantee that best practices across Europe were upheld. The difficulties encountered during this process related to the diversity of certification criteria and the varying educational opportunities across Europe. Countries such as the United Kingdom offer master's degrees in 
applied sport psychology, whereas in other countries there is no possibility to attend university courses in sport psychology no certification systems exist. FEPSAC’s rationale was to set criteria that could be met by a large number of member countries, that would ensure a minimum quality, and that would also allow members from such regions as Eastern European countries to meet the certification criteria. The decision was made to focus on a minimum quality level rather than the highest level so that the certification could be applied Europewide and be inclusive of members from countries with few educational opportunities. Furthermore, the decision was made to keep the costs for becoming certified as low as possible and to offer reduced fees to applicants from economically disadvantaged areas. Eligibility criteria for FEPSAC Certification. The eligibility criteria for FEPSAC certification are based on an intensive analysis of the postgraduate certification systems in European countries (Hutter et al., 2016; Wylleman, Harwood, Elbe, Reints, \& Caluwé, 2009) plus discussions with AASP and ISSP. Applicants for the European-wide certification are to document a higher education qualification, a specialization in sport psychology, supervised applied practice, a commitment to culturally-competent practice in sport and exercise psychology and a commitment to ethical practice.

A higher education degree provides the specialist with a broad science-based background knowledge, upon which to build the specialization in applied sport and exercise psychology. A bachelor and master's degree or equivalent, with a minimum of a total of 240 ECTS (1 ECTS corresponds to 28 hours of work) is expected. The training background as a whole must involve the following areas: sport science, sport psychology, or psychology. At least 60 ECTS shall be in any of the three areas mentioned above as part of a master's degree. The sport psychology specialization provides practitioners with science-based knowledge in sport psychology and complements the initial higher education qualification with knowledge of subject areas not otherwise sufficiently covered. Therefore, applicants 
with a background in psychology and sport science need to document further education, postgraduate study, or continuous professional development (CPD) totaling 30 ECTS in areas of sport psychology complementary to their qualification.

Furthermore, applicants need to document 250 hours of practice. This should include individual, group or team consultation, and educational activities in the form of applied sport psychology presentations to athletes, coaches, referees, or athletes' parents. Within the above documented group and individual consultations, at least 10 hours should be training and competition experience, as interventions at a competition, on-site exposure, and/or observation. The documented practice should be part of the supervised experience, consisting of at least 50 hours. Supervision and intervision provides practitioners with the guidance of other practitioners and peers who offer feedback and secures competence in the applied practice of the applicant. It is encouraged to focus supervision practices on indirect supervision with case management (see Watson et al., 2004). These hours should include at least 50 of the 250 hours of documented practice with supervision and intervision, including at least 20 hours of individual supervision with an approved supervisor, 20 hours of group supervision with an approved supervisor, and a maximum of 10 hours of peer intervision of documented meetings with experienced colleagues/peers in sport psychology counseling. Given that FEPSAC is a European organization and this is a European-wide accreditation it is important to ensure that applicants can document a European component in their education and their commitment to culturally-competent practice. Hence, applicants need to document international elements in their education and applied practice and to read and sign their commitment to FEPSAC's position stand on culturally-competent practice in sport and exercise psychology. Examples of international elements are: participation in European-facing activities (e.g., active participation in European workshops, events, or forums, and/or membership of a Europe-based international sport psychology society; 
language skills other than one's native language; a period of residency abroad for at least four months, or professional activity with stakeholders from different countries).

$$
\text { Additionally, applicants need to read and sign their commitment to FEPSAC's }
$$

position stand on ethical principles. These criteria were approved at the FEPSAC's members meeting on November 28, 2017 and after that a testing phase in which candidates can submit their documentation to FEPSAC will be initiated. Subsequent to a successful testing phase certification shall begin in 2019 .

\section{Association for Applied Sport Psychology (AASP)}

Sport psychology in North America traces to a few key contributors. Norman Triplett is credited with publishing the first sport psychology (and social psychology) research article in 1898 when he investigated the impact of performing a task either alone or in the presence of others (i.e., social facilitation effect). Coleman Griffith is often cited as “America’s First Sport Psychologist” (Green, 2012). Griffith started the "Research in Athletics Laboratory” at the University of Illinois in 1925, where he studied the psychology of performance within athletics. In 1937, Griffith was hired by Phillip K. Wrigley to work with the Chicago Cubs, with the goal of giving the team an advantage to help them win games during the 1938 season. Griffith also authored several books and articles that helped to advance the importance of psychology within athletic performance. Following in the applied footsteps of Coleman Griffith, Bruce Ogilvie is often considered the "Father of North American Applied Sport Psychology” based upon his role conducting research on athletics and consulting with Olympic and professional teams during the 1960s-2003 (Weinberg \& Gould, 2015). In the early years of sport psychology, the focus of many professionals was on laboratory research, rather than applied practice with athletes (Silva, Metzler, \& Lerner, 2011). This laboratory focus was especially evident within members of the North American Society for the Psychology of Sport and Physical Activity (NASPSPA), which was the only 
major sport psychology professional organization in North America until 1986. In 1986, the Association for the Advancement of Applied Sport Psychology (AAASP; now Association for Applied Sport Psychology, AASP) was formed, followed closely by Division 47 of the American Psychological Association, also founded in 1986. A large impetus for the formation of AAASP occurred in 1984, when NASPSPA voted not to address issues related to the practice of applied sport psychology (Silva et al., 2011).

AAASP was formed to promote science and ethical practice in the field of sport and exercise psychology, while providing an opportunity for individuals to share information related to theory development, research, and the provision of psychological services to consumers. AASP has dedicated a great deal of effort and assumed a great deal of accountability towards the goal of advancing the work of practitioners with the goal of improving the performances of individuals across a broad array of performance settings. Certification of applied practitioners and accreditation of graduate programs to effectively train future professionals were goals of the organization from its inception (Weinberg, 1989). The process of codifying the standards of professional preparation and practice in sport psychology has been met with attention and controversy. Within AAASP, the development of a certification program was made difficult by the need to serve those who were working and those who wished to enter the profession (Zizzi, Zaichkowsky \& Perna, 2002).

AASP certification. AASP's certification program was approved in 1989 during its annual conference in Seattle, Washington. However, the certification program officially began in 1992. The credential mark was set as "Certified Consultant - Association for the Advancement of Applied Sport Psychology” (CC-AAASP). While the preferred title was “sport psychologist” or “sport psychology consultant”, there was concern about violating state or provincial laws (Zizzi et al., 2002), which led the organization to use CC-AAASP. AAASP wanted to create a certification to identify professionals who possessed the minimal 
competencies and experiences necessary to practice (Silva et al., 2011). This initial program involved compromise between sport science and psychology professionals to develop a system that satisfied both groups. Then, the program committee certified an initial group of members using a grand parenting system, and developed a process for certifying practitioners. The initial certification utilized a portfolio review process. To be certified, individuals needed only to provide portfolio evidence of having met the certification requirements. These certification requirements included the completion of a doctoral degree from an accredited institution, 400 hours of supervised experience providing sport psychology services under the supervision of a qualified person, completion of 13 specific courses from 11 identified content areas, and have sport experience (skills, techniques and analysis through sport participation or coaching). In 2002 provisional certification was approved, allowing individuals with master's degrees to be provisionally certified, but requiring them to receive an additional 300 hours of supervised experience before they were fully certified (Silva et al., 2011). This certification program served the organization and profession extremely well for 25 years with little change. In 2011, then President Jack Lesyk created the Future of Certification Ad Hoc Committee (FCAHC) to evaluate the certification program and make suggestions to meet the strategic plan and strengthen the certification program to enhance credibility of the industry and promote members to the general public (Watson \& Castillo, 2014). The FCAHC reviewed the certification with the purpose of proposing changes to strengthen the program and make it more valuable to members and those seeking the services of sport and exercise psychology consultants. The primary recommendations of the FCAHC were: (1) certification should meet National Commission for Certifying Agencies (this is the primary agency for accrediting certifications in the United States, with a long history of promoting certification development) standards, meaning that an exam-based certification was necessary, (2) Continuing education units (CEUs or CPD) should be used to help maintain practitioners' 
competencies, (3) portfolio review should remain part of the certification process, (4) graduate education and other alternative means of demonstrating knowledge should be used, (5) the certification should focus on north American based practitioners to start, but later expand to include international certification, and (6) it would be best to carry out two Job Task Analyses to determine whether sport/performance consultation utilizes the same as processes as exercise/health consultation (Watson \& Castillo, 2014).

These issues led to debate among Past-Presidents, Fellows and the membership. However, in time, a Job Task Analysis was approved and completed in June 2015 as a preliminary step to exam creation (Rosen \& Lipkin, 2016). Following the 2015 annual conference, a motion was passed and approved by the Fellows to allow for the creation of an autonomous Interim Certification Council charged with creating policies and procedures that would be used to develop an autonomous permanent certification council, certification program, and the creation of a certification exam. Based upon the recommendations of this interim certification council, a constitutional amendment was passed at the 2016 annual conference in Phoenix, Arizona, that would allow for the creation of an autonomous certification council, create a governance charter that would guide the new certification council, and create a timeline for the transition to the new certification council and development of a policies and procedures document to govern the updated certification program. Following the approval of this amendment, the interim certification council finalized the creation of the initial exam. It was during this time that the certification credential and mark was modified to Certified Mental Performance Consultant (CMPC). The permanent Certification Council was chosen in 2017 to implement the accreditation standards. Eligibility criteria for CC-AASP. In the year between the 2016 and 2017 annual conferences, many decisions were made by the Interim Certification Council and later Certification Council to meet the criteria for the NCCA accreditation standards (see Table 1 
for summary). The CMPC program requires applicants to first prove that they have met all

485 eligibility requirements before they are allowed to take the certification exam. The Certification Council's intention is to apply for accreditation from the National Commission for Certifying Agencies in 2019 after the updated certification has been in place for a year.

\section{International Society of Sport Psychology (ISSP)}

The International Society of Sport Psychology has long been interested in accreditation. The ISSP was first launched in 1965, led by Italian sport psychologist Ferruccio Antonelli, concurrent to an international conference, held in Rome. Nearly 450 delegates attended this event, titled “The First World Congress of Sport Psychology” (Morris, Hackfort, Lidor, 2003). During this conference a business meeting was held, which in turn led to the formalization of the ISSP. Five years later, in 1970, the International Journal of Sport Psychology was launched, and it became the society's flagship journal, remaining as such until 2003 when the International Journal of Sport and Exercise Psychology assumed this designation. Hence, within the first 20 years of ISSP existence, the society's focus was on the congress and its peer reviewed journal, to advance the field, worldwide (Morris et al., 2003).

Though we find little evidence regarding a focus beyond scientific advancement within the ISSP for the first 30 years of its existence, the society's mandate has slowly begun to broaden (see Lidor, Morris, Bardaxoglou, Becker, 2001). This shift was expedited when the 1997 ISSP Managing Council struck a committee to examine the development of the field from the vantage of professional practice services (Tenenbaum, Lidor, Papaioannou, \& Samulski, 2003). Four years later, in 2001, Tony Morris chaired a special session devoted to the topic of professionalization, and there it was decided that the ISSP would provide recommendations that further societies might consider in relation to their accreditation systems. Since 2001, the ISSP has been on a slow and steady course that has brought the society to its current identity that now more actively bridges science and practice. Within the 
World Sport Psychology Sourcebook that many mid-career professionals can recall from their graduate studies, sport psychology programs were identified for their strengths, which included practical applications. Two years afterward, Morris, Alfermann, Lintunen, and Hall (2003) authored Training and Selection of Sport Psychologists: An International Review. During this initial sojourn in the applied realm, it at least appears that the ISSP was positioning itself at arm's length from accreditation, rather proposing conceptual suggestions for regional and national accrediting bodies to consider: Morris et al. wrote: The Managing Council of the International Society of Sport Psychology ... has a responsibility to examine the development of sport and exercise psychology around the world and to state its position with regard to the way that sport psychologists are trained and selected to work in service provision in a range of contexts (p. 139).

The authors proceeded to explain that "The conviction of the ISSP is that by trying to understand the ways by which sport psychology is emerging internationally, groups like ISSP will be in a stronger position to provide appropriate advice and support” (p. 140). The authors found that a divide existed when the knowledge base, capacities, and types of competencies utilized of developed countries were compared with developing, or what the ISSP has recently recast as, emerging countries (Schinke, Papaioannou, Schack, 2016). Competencies and standards were then proposed in a concurrent paper, in relation to sport and exercise psychology practice (see Tenenbaum et al., 2003). These competencies included knowledge base standards garnered through formal education (i.e., theories, scientific/research tools, measurement, assessment, and/or interpretation) and practice standards (i.e., interventions and communication skills).

The arm’s length conceptual course remained the ISSP's approach until 2013, when then ISSP President Gangyan Si proposed that it needed to enter into formal accreditation development. President Si’s reasoning aligned with the initial mandate of the ISSP to grow 
sport psychology on a world scale, beyond the regional developments that were then rapidly developing. He and the 2013-2017 Managing Council then began to discuss and develop accreditation, where Artur Poczwardowski was appointed as the Society’s inaugural accreditation chair. The accreditation committee began to consider global standards and explore what might be an appropriate threshold, or standard, across the world, spanning developed and developing countries. Chris Harwood assumed the role of accreditation chair in 2017. Below, the ISSP provides five years of work, with the progress in this work increasing steadily. The intention now is to launch the ISSP Registry in 2018. ISSP registry (ISSP-R). As part of the focus on globalization and collaboration on matters associated with high quality professional practice, the ISSP Accreditation Committee is presently establishing an internationally recognized consultant registry. It is envisioned that the ISSP-R will respond to the high international mobility of both sporting clients and consultants as well as increase the visibility and credibility of the profession internationally. Importantly, there is recognition that many countries possess no formalized program for quality assuring the ethical and professional provision of sport and exercise psychology services to athletes, coaches, parents and organisations. A particular focus is on supporting those countries in which applied sport psychology is in a developing phase and augmenting professional standards in sport psychology practice to a minimum, satisfactory level.

Eligibility criteria for ISSP-R. Academic qualifications, underpinning knowledge, practical delivery and service-based experiences form the core criteria of eligibility to apply for ISSP-R status. Applicants will be required to submit evidence, as part of their application, in the following areas denoted in Table 1. Beyond appropriate academic qualifications at BSc and MSc level with substantive coverage of sport and exercise psychology, applicants will be asked to submit evidence of supervised practice hours with individuals and teams. This will also include a concise portfolio of applied practice that illustrates examples of client case 
work, their philosophical approach and reflections on self-development. Aligned with the specific interests of ISSP, a number of short ISSP-specific modules are envisaged that will require applicants to engage with learning resources on cultural competence, ethical competence in line with the ISSP ethics code, and knowledge related to mental health. As quality of supervision is a key factor in professional accreditations, ISSP is focusing on the development of supervisor training processes in order to build a registry of ISSP-R approved supervisors. Applicants seeking ISSP-R status will require supervision from an ISSP-R approved supervisor to assist with the quality control of supervised practice. Supervisors will be required to confirm the practice hours completed by their supervisee(s), verify the supervised hours (minimum 40 hours), and endorse their supervisee's competence to practice independently.

Accreditation of national associations. Although many sport psychologists may apply to the Registry from countries without a national accreditation program, the ISSP aims to accredit national organisations whose existing sport psychology accreditation programs meet the knowledge, practice and supervision standards outlined above. Such organisations will be required to apply to ISSP and submit evidence to this effect. An organization that is successfully endorsed and quality assured by ISSP will then be able to pass this benefit onto its accredited members. In this case, subject to ISSP membership and reduced application fees, ISSP-R status will be automatically conferred to the nationally accredited member. Such practitioners will still be required to complete the short ISSP-specific modules but extended time will be allocated for completion (i.e., within 12 months of ISSP-R).

Finally, the ISSP envisages that renewal of registry status will be applicable every six years and an ISSP Continuing Education Program (CEP) will be designed to help facilitate this requirement. Specific criteria are likely to reflect: (1) evidence of continuing practice and 
583 (2) engagement with a certain number of ISSP Accreditation Committee approved CEP

584 workshops or webinars and national/international conference attendance.

585

586

587

588

589

590

591

592

593

594

595

596

597

598

599

600

601

602

603

604

605

606

607

\section{Synthesized Postulates}

The co-authors from four international societies have considered their approaches to accreditation. The societies enlisted were the ASPASP, FEPSAC, ISSP, and AASP. These societies entered into this discussion for distinct reasons. First, the societies are actively engaged in the development of accreditation systems. Second, these societies are well established, having extensive histories from which to understand and compare approaches to accreditation from the lens of where they are located and how their engagement in accreditation began. With these points in mind, we propose postulates to guide further discussions about the present status and future directions of sport psychology accreditation.

1. Accreditation systems develop over time, and so are dynamic, not static. Dependent on a society’s identity, it might transition immediately or gradually into having an accreditation system. Societies that prioritize science and knowledge generation might be slow in this journey, or they might not enter into accreditation at all. There are also societies that initially or eventually identify themselves as science based, though practically minded. Societies that incline toward practice become candidates for accreditation. Despite inclinations, there appears to be a societal pathway followed in our field beginning with conferences and peer-reviewed outlets. Such societies then tend to embark on accreditation, having built their scientific credibility.

2. Educational opportunities in international sport and exercise psychology societies can (and must) take on several different formats, partly explained by temporally-situated organizational developments. These developments have included online courses, certification, or registry status. The latter two options appear to be preferred as eventual outputs, with all four societies focusing on certification or registry systems. 
3. There ought not to be judgement regarding a certification or registry status approach being of better or worse quality when accreditation systems are compared. Each societal accreditation, and for that matter, any national approach to accreditation, will reflect a specific historical backdrop and a current/local status in terms of professional development. Several countries or regions will have more access to educational and supervision/mentoring, and some have less. Across the four societies and the regions they are seeking to assist, however, there is a commitment to the provision of ethical training and supervision, though in the case of the latter, requirements will vary by society dependent on its mission.

4. The importance of cultural nuances within any form of accreditation must be carefully considered and embedded within skill formation. All four societies agree that a form of cultural sport psychology training is necessary for their accreditation. In some cases, the argument has been made that cultural training should blend eastern and western approaches (i.e., ASPASP), or a multicultural approach (i.e., AASP, FEPSAC), or a localized approach that is dependent on the country where the practitioner resides (i.e., ISSP). These three derivatives advocate inclusiveness, whilst also reflecting the regions and candidates they have respectively targeted.

5. Key competencies remain the core of accreditation systems in sport and exercise psychology, regarded herein to be inclusive of professionals with psychology and sport science backgrounds. These competencies must tie to theoretical knowledge, sound scientific approaches, assessment skills, intervention techniques, personal skills, and a deep knowledge of professional ethics and suitable cultural sport psychology/diversity skills training. Added to these competencies could be sociopolitical and economic considerations that recognize the idiosyncratic locations where the accredited work. To achieve this purpose, we propose that accreditation 
committees be inclusive of perspectives from the profession's stakeholders, such as

634

635

636

637

638

639

640

641

642 national sport organizations and Olympic committees in order to consider the perspectives of potential consumers.

6. Though only AASP has considered the role of universities and graduate programs in the augmentation of such competencies, this tie in with academic institutions must become a necessity. The responsibility in sport psychology training must extend beyond societies and aspiring professionals to formal educational institutions, so as to further professionalize our field, beyond its strengths in theories and scientific knowledge. 


\section{References}

644 Adams, S. A. (2006). Does CACREP accreditation make a difference? A look at NCE results 645 and answers. Journal of Professional Counselling: Practice, Theory, and Research, 34, 60-76.

\section{7}

648

649

650

651

652

653

654

655

656

657

658

659

660

661

662

663

664

665

666

667

Asian-South Pacific Association of Sport Psychology. (n.d.). Professional development. Retrieved from http://www.aspasp.org/professional-development/

Association for Applied Sport Psychology. (2016). 2016-2018 balanced scorecard. Retrieved from http://www.appliedsportpsych.org/site/assets/files/1031/aasp20162018strategicplan.pdf

Association for the Advancement of Applied Sport Psychology. (1995). A new USOCAAASP Partnership. AASP Newsletter, 10(3), 9.

Association for Applied Sport Psychology. (n.d.). Become certified. Retrieved from http://www.appliedsportpsych.org/certification/become-certified/

Association for Applied Sport Psychology (n.d.). Our history. Retrieved from http://www.appliedsportpsych.org/about/our-history/

Bäumler, G. (2002). Sportpsychologie zwischen 1884 und 1900/Die Generation der Pioniere. [Sport psychology between 1884 and 1900/The generation of pioneers]. In G. Bäumler, J. Court, \& W. Hollmann (Eds.), Sportmedizin und sportwissenschaft. historischsystematische facetten. [Sport medicine and sport science. Historical and systematical facets] (pp. 287-318). Sankt Augustin, Germany: Academia.

Ding, X., Han, B., Yin, H., Lu, M., Xu, X, \& Zheng, M. (2014). Mental training of the Chinese gymnastics team in preparation for the Beijing Olympic Games. In P. C. Terry, L. Zhang, Y. Kim, T. Morris, \& S. Hanrahan, (Eds.), Secrets of Asian sport psychology (pp. 147-167). Toowoomba, Australia: Asian-South Pacific Association of Sport Psychology/University of Southern Queensland. Retrieved from 
668

669

670

671

672

673

674

675

676

677

678

679

680

681

682

683

684

685

686

687

688

689

690

691

692

http://docs.wixstatic.com/ugd/9b5325_4b44d0ff964c47c4924d1c92b88cd6b9.pdfEpstei n, R. M., \& Hundert, E. M. (2002). Defining and assessing professional competence. Journal of the American Medical Association (JAMA), 287, 226-235. doi:10.1001/jama.287.2.226

European Federation of Sport Psychology. (n.d.). Certification. Retrieved from http://www.fepsac.com/certification/

Fouad, N. A., Hatcher, R. L., Hutchings, P. S., Collins Jr., F. L., Grus, C. L.,...Crossman, R. E. (2009). Competency benchmarks: A model for understanding and measuring competence in professional psychology across training levels. Training and Education in Professional Psychology, 4(3 suppl.), S5-S26. doi:10.1037/s0015832

Green, C. D. (April, 2012). America’s first sport psychologist. APA Monitor, 43(4), 22. Retrieved from http://www.apa.org/monitor/2012/04/sport.aspx

Hofstede, G. (1980). Culture’s consequences: International differences in work-related values. Beverly Hills, CA: Sage.

Hutter, V. (2014). FEPSAC Newsletter. Psychology of Sport \& Exercise, 15, 226. doi:10.1016/j.psychsport.2013.12.001

Hutter, R. I., van der Zande, J. J., Rosier, N., \& Wylleman, P. (2016). Education and training in the field of applied sport psychology in Europe. International Journal of Sport and Exercise Psychology. Advanced online publication: https://doi.org/10.1080/1612197X.2016.1162189

International Society of Sport Psychology. (n.d.). The ISSP consultant registry (ISSP-R). Retrieved from https://www.issponline.org/issp-r .

Jordan, K. (2015). Massive open online course completion rates revisited: Assessment, length and attrition. International Review of Research in Open and Distributed Learning, 16, 341-358. https://doi.org/10.19173/irrodl.v16i3.2112 
693 Kellmann, M., Gröpel, P., \& Beckmann, J. (2011). Evaluation und qualitätsoptimierung der 694 sportpsychologischen betreuungsarbeit im Deutschen spitzensport [Evaluation and quality optimization of sport psychological coaching in German high performance sport]. Zeitschrift für Sportpsychologie, 18, 49-59. doi:10.1026/1612-5010/a000040

697

698

699

700

701

702

703

704

705

706

707

708

709

710

711

712

713

714

715

716

Kunath, P. (2003). Psychology and sport: A historical review. In E. Apitzsch, \& G. Schilling (Eds.), Sport psychology in Europe. FEPSAC - An organisational platform and a scientific meeting point (pp. 20-26). Biel, Switzerland: FEPSAC.

Lidor, R., Morris, T., Bardaxoglou, N., \& Becker Jr., B. (2001). The world sport psychology sourcebook ( $3^{\text {rd }}$ ed.). Morgantown, WV: Fitness Information Technology.

Martin, N. I, Kelly, N., \& Terry, P. C. (2018). A framework for self-determination in massive open online courses: Design for autonomy, competence, and relatedness. Australasian Journal of Educational Technology, 34, 35-55. https://doi.org/10.14742/ajet.3722

Morris, T., Alfermann, D., Lintunen, T., \& Hall, H. (2003). Training and selection of sport psychologists: An international review. International Journal of Sport and Exercise Psychology, 1, 139-154. https://doi.org/10.1080/1612197X.2003.9671708

Morris, T., Hackfort, D., \& Lidor, R. (2003). From hope to pope: The first twenty years of ISSP. International Journal of Sport and Exercise Psychology, 1, 119-138. https://doi.org/10.1080/1612197X.2003.9671707

Rooney, A. L., \& van Ostenberg, P. R. (1999). Licensure, accreditation and certification: Approaches to health services quality: Quality assurance methodology refinement series. Bethesda, MD: US Aid. Retrieved from https://www.usaidassist.org/sites/assist/files/accredmon.pdf

Rosen, G. A., \& Lipkins, R. H. (2016). Sport psychology certification job task analysis and validation prepared for the Association for Applied Sport Psychology. Retrieved from 
http://www.appliedsportpsych.org/site/assets/files/30025/cmpccandidatehandbook_20 17-11.pdf

Ryba, T. V., Stambulova, N. B., \& Wrisberg, C. A. (2005). The Russian origins of sport psychology: A translation of an early work of A. C. Puni. Journal of Applied Sport Psychology, 17, 157-169. https://doi.org/10.1080/10413200590932461

Schinke, R. J., Papaionnou, A. G., \& Schack, T. (2016). Sport psychology in emerging countries: An introduction. International Journal of Sport and Exercise Psychology, 14, 1-7. https://doi.org/10.1080/1612197X.2016.1155828

Si, G., Yue-Li, H., \& Chen, B. (2016). China. In R. J. Schinke, K. R. McGannon, \& B. Smith (Eds.), Routledge international handbook of sport psychology (pp. 36-46). Abingdon, UK: Routledge.

Silva, J. M (1984). The emergence of applied sport psychology contemporary trends: Future issues. International Journal of Sport Psychology, 15, 40-51.

Silva, J. M., Metzler, J. N., \& Lerner, B. (2011). Training professionals in the practice of sport psychology ( $2^{\text {nd }}$ ed.). Morgantown, WV: Fitness Information Technology.

Stambulova, N., Johnson, U., \& Linner, L. (2014). Insights from Sweden: Halmstad applied sport psychology supervision model. In J. G. Cremades \& L. S. Tashman (Eds.), Becoming a sport, exercise, and performance psychology professional: A global perspective (pp. 276-284). New York, NY: Psychology Press.

Tenenbaum, G., Lidor, R., Papaiannou, A., \& Samulski, D. (2003). ISSP position stand: Competencies (occupational standards, knowledge, and practice) and their accomplishment (learning specification, essential knowledge, and skills) in sport and exercise psychology. International Journal of Sport and Exercise Psychology, 1, 155166. https://doi.org/10.1080/1612197X.2003.9671709 
741 Terry, P. C. (2011). Applied sport psychology: Beware the sun, Icarus. In P. R. Martin, F. M.

742 Cheung, M. C. Knowles, M. Kyrios, L. Littlefield, J. B. Overmier, \& J. M. Prieto (Eds.), 743 The IAAP handbook of applied psychology (pp. 386-410). Oxford, UK: Blackwell.

744 Terry P. C., \& Martin N. I. (2015). Elite sport performance: Psychological perspectives.

$745 \quad$ Retrieved from http://www.elitesportpsy.org.au .

746 Terry, P. C., Zhang, L-W., Kim, Y., Morris, T., \& Hanrahan, S. (Eds.). (2014). Secrets of 747 Asian sport psychology. Toowoomba, Australia: Asian-South Pacific Association of 748 Sport Psychology/University of Southern Queensland. Retrieved from 749 http://peterterry.wixsite.com/books/secrets

Watson II, J., \& Castillo, S. (2014). Future of Certification Ad Hoc Committee: Summary of information. Presented at the 2014 Annual Conference of the Association for Applied Sport Psychology, Las Vegas, NV.

Weinberg, R. S. (1989). Applied sport psychology: Issues and challenges. Journal of Applied Sport Psychology, 1, 181-195. https://doi.org/10.1080/10413208908406414

Weinberg, R., \& Gould, D. (2015). Foundations of sport and exercise psychology (6 $6^{\text {th }}$ Ed.). Human Kinetics. Champaign.

Wylleman, P., Harwood, C. G., Elbe, A.-M., Reints, A., \& Caluwé, D. de (2009). A perspective on education and professional development in applied sport psychology. Psychology of Sport and Exercise, 10, 435-446. https://doi.org/10.1016/j.psychsport.2009.03.008

Vanden Auweele, Y. (2003). Sport psychology and education. The European masters in exercise and sport psychology. In E. Apitzsch, \& G. Schilling (Eds.), Sport psychology in Europe. FEPSAC - An organisational platform and a scientific meeting point (pp. 38-48). Biel, Switzerland: FEPSAC. 
765 Zaichkowsky, L. D., \& Perna, F. M. (1996). Certification in sport and exercise psychology. In J. L. Van Raalte \& B. W. Brewer (Eds.), Exploring sport and exercise psychology (pp. 395-411). Washington, DC: American Psychological Association.

768 Zhang, L. (2017). Is a peaceful mind a winning mind? Comment on Hardy et al. (2017). Progress in Brain Research, 232, 187-190. https://doi.org/10.1016/bs.pbr.2016.12.005

Zizzi, S., Zaichkowsky, L., \& Perna, F. M. (2002). Certification in sport and exercise psychology. In J. L. Van Raalte \& B. W. Brewer (Eds.), Exploring sport and exercise psychology (pp. 459-477). Washington, DC, US: American Psychological 


\section{Table 1}

776 Accreditation requirements of ASPASP, FEPSAC, AASP, and ISSP

\begin{tabular}{crl}
\hline Qualifications and knowledge base & Service experiences and supervision \\
\hline & ASPASP & \\
\hline
\end{tabular}

Requirements vary across the region

Australia requires registration as a psychologist and practice endorsement in sport and exercise psychology, requiring an accredited doctorate and 1 year internship; or an accredited masters and 2 year internship, or equivalent (Psychology Board of Australia)

In Korea, Level 1 accreditation requires a doctoral degree closely related to sport psychology (intentionally flexible and inclusive of sport science), completion of a prescribed educational curriculum, and passing a written examination (Korean Society of Sport Psychology)

In China, Level 1 accreditation requires a doctoral degree closely related to sport psychology (intentionally flexible and inclusive of sport science) or position at associate professor or above; two international peerreviewed papers as first author; and passing an oral examination (China Sport Psychology Association)

For countries without a national accreditation system, free online professional development resources are provided by ASPASP (open access book, open access course in sport psychology, flexibly defined to include psychology and sport science) as a step towards regional accreditation

BSc and MSc degree in psychology, sport science or sport psychology (240 ECTS)

Postgraduate courses, workshops or legally established programs in sport psychology (30 ECTS)

Read and sign commitment to FEPSAC's position stand on culturally-competent practice in sport and exercise psychology

Read and sign commitment to FEPSAC's position stand on ethical principles
At least 1,360 hrs of supervised practice, 80 hrs supervision from an approved supervisor, and 60 hrs professional development (1-year internship). At least 2,720 hrs of supervised practice, 160 hrs supervision, and 120 hrs professional development (2-year internship) At least 200 hours of supervised experience, two case presentations at academic conferences, and 50 hours of professional development

At least 400 hours of supervised practice and 5 years consulting experience

Development of a mental training program for one of eight hypothetical athletes, presenting with specific psychological issues
250 documented hours of practice in diverse settings

50 hours of supervised practice including 20 hours of individual supervision with an approved supervisor, 20 hours of group supervision with an approved supervisor, and a maximum of 10 hours of peer intervision of documented meetings with experienced colleagues/peers in sport psychology consulting

Documentation of international elements in one's applied practice 
Documentation of international elements in one's education
For all applicants, membership of FEPSAC is required, an application fee will be levied and CPD credits will be required for re-certification

\begin{tabular}{l}
\hline Master's or doctoral degree from a regionally- \\
accredited institution in an area clearly related to \\
sport science or psychology \\
Completion of eight specific courses covering \\
content related to specific knowledge areas: \\
K1) Professional Ethics and Standards; K2) \\
Sport Psychology; K3) Sport Science; K4) \\
Psychopathology; K5) Helping Relationships; \\
K6) Research Methods and Statistics; K7) \\
Psychological Foundations of Behavior; and \\
K8) Diversity and Culture
\end{tabular}

Successfully pass a 100 -item exam designed to assess knowledge of the practice of applied sport psychology, as developed from the previous job task analysis

Agreement to adhere to the principles and standards of the AASP Ethics Code

Experienced Practitioner Pathway:

Allows those who have master's or doctoral degree from a regionally-accredited institution in an area clearly related to sport science or psychology and have worked for $10+$ years postgraduation in applied sport psychology to apply for certification. Must show significant knowledge of the field through engagement in professional development and be able to show evidence of having received mentorship, supervision, consultation.

Must pass the 100-item certification exam. Must agree to adhere to the principles and standards of the AASP Ethics Code
Documentation of completion of a 400-hour mentored experience (Minimum of $200 \mathrm{hrs}$ of experience with sport population):

Minimum 200 hrs of direct client contact; Maximum of 150 hrs of time spent in support activities; Minimum of 50 hrs of mentorship, with minimum of 40 hrs of face-to-face (minimum of $30 \mathrm{hrs}$ ) and/or electronic mentorship, and a minimum of $10 \mathrm{hrs}$ of live/video session observation

Recertification Processes (Every 5 years): Completion of 75 continuing education units (CEUs) within the 5-year certification period. At least 6 CEUs in each of the following required continuing education areas: professional ethics, diversity, and mentorship/supervision (required for mentors only)
BSc degree in psychology, sport science or a related field

MSc degree in an area directly related to psychology or sport science

(This programme will require evidence of substantial credits in sport and exercise psychology)

ISSP cultural competence module (Prerequisite readings/webinar and learningbased reflections)
A minimum of 250 hours of direct delivery while under the guidance of a supervisor /mentor (i.e., supervision): Minimum of 150 hrs of one to one work; Minimum 25hrs of team/group-based work. This will be counted Post-MSc qualification

Reflective portfolio of case work: Concise portfolio with case study summaries, developmental self-reflections and espoused philosophy and model of practice 
ISSP ethical competence module (Prerequisite readings/webinar and learningbased reflections)

ISSP mental health module (Prerequisite readings/webinar and learningbased reflections)
Evidence of Supervision Meetings and Observation: A minimum of 40 hours of supervision (i.e., one session per six hours of client consultation; monthly supervision over 12 years; observation of supervisee in practice (in vivo, via video, etc.)

Supervisory endorsement of professional competence

(i.e., Supervisor letter providing satisfactory evaluation of professional competence)

For all applicants, membership of ISSP is required, an application fee will be levied and CPD credits will be required for re-registration after 6 years 